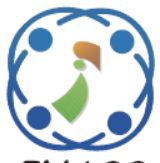

\title{
Droop Control of Bi-Directional DC-DC Converter for Improved Voltage Regulation and Load Sharing in DC Microgrid
}

\author{
Narasimha Prasad Tulasi ${ }^{1 *}$ \\ Lakshmi Devi Aithepalli² \\ ${ }^{1}$ Department of Electrical \& Electronics Engineering, \\ PVP Siddhartha Institute of Technology, Vijayawada, Andhra Pradesh, India \\ ${ }^{2}$ Department of Electrical \& Electronics Engineering, S.V. University, \\ Tirupati, Andhra Pradesh, India \\ * Corresponding author's Email: narasimhaiete@gmail.com
}

\begin{abstract}
DC microgrids are gaining popularity as most of the residential loads like Televisions, BLDC fans, LED bulbs, Mobile phones and other electronic gadgets are DC in nature, but to connect Distributed DC generator (DG) to DC bus, DC-link voltage is to be maintained at the reference value. In the proposed work, a transformer coupled dual input converter control strategy is modified by replacing existing Perturb \& Observe Maximum power point tracking controller with $V-d p / d v$ based droop controller, which amalgamates DC bus voltage regulation and Maximum power point tracking (MPPT) of PV source and battery state of charge (SOC) in single controller, and eluding controller switching between voltage regulation and MPPT modes. The proposed system will also work as Decentralized droop control for load sharing, and applicable for both islanded and grid-connected operations. Load Power sharing between DG sources is achieved according to its droop coefficient values in DC side of the inverter, thus suitable for DC Microgrid, and results are verified by simulating the above system in MATLAB/Simulink.
\end{abstract}

Keywords: Isolated type transformer coupled boost converter, Single phase VSI based PV system, Solar and battery based PV system, DC microgrid, Droop control, $-d p / d v$, Load sharing.

\section{Introduction}

Photovoltaic (PV) source is one of the significant players in the world's energy portfolio, which will be one of the biggest contributions to electricity generation among all the renewable sources. Hence, it is a challenge to supply stable and continuous power using these sources. This can be addressed by efficiently integrating energy storage elements. Further, such systems must require power electronic converters to form an interface between the PV array, the battery and the load/grid.

The main focus of the work is on DC bus voltage regulation and load sharing between distributed generators (DG) for DC microgrid. Solar irradiation is time varying in nature and there is a necessity to track its maximum power point (MPP) all the time for effective utilization. It requires a DC-DC converter, backup storage such as a battery is also necessary to meet the load requirements under low light conditions. Thus, it needs another dc-dc converter for battery charge/discharge control, and for conversion of DC to $\mathrm{AC}$, one more converter is required [1]. But this increases switching losses and overall cost of the system and reduces reliability. When isolation is nonuniform, ordinary MPPT algorithms doesn't hold good, complex MPPT algorithm are required [2]. In [3], an isolated multiport dc-dc converter is discussed for simultaneous power management of multiple and different types of renewable energy sources and converter, which are useful for MPPT control of a wind/solar hybrid generation systems. A method in which the use of separate dc-dc converter for MPPT action is avoided and is projected in [4], Similar approach has also been reported in [5], for application in grid-connected scheme. Nevertheless, the aforesaid schemes have to bypass the PV array by a diode and an inductor when PV power goes to zero. 
This results in overall gain reduction as PV and battery are connected in series. In [6,7], a transformer coupled dual-input converter is proposed in order to tackle these issues of MPPT and battery charging /discharging control and it is followed by a conventional full bridge inverter, meant for residential applications. But in this control strategy, control switching is done between PV and battery to maintain DC bus voltage regulation. In [8], to feed the dc loads, a low capacity multi-port converter for a hybrid system is presented. This has PV array and battery linked in series and is intended for the photovoltaic powered lighting system. However, the existence of resonant elements make it sensitive to parameter variation, acceptable variation in the duty ratio of the switches is constrained within a specific range, and voltage gain is rather limited. Typically, load sharing amongst different DGs is based on its individual power ratings. In microgrids, control is separated as primary, secondary and tertiary controls [9]. Tertiary control is the system level control which does the energy management within the microgrid and provides essential power references for different DGs. Secondary control takes power references from the above i.e., tertiary level and controls power by regulating the bus voltages and shares the current among DG sources according to their rating, and Primary control is controlling voltage or current of a particular DG, i.e., it offers device level control for power converters. The Power developed by one DG reduces due to its inherent weather dependent nature, causes unequal voltages, and reduces system load sharing accuracy. In [10] the slope of the droop curve is adjusted to circumvent this problem. In [11, 12] Master-slave control technique is projected for droop control in Islanded microgrids, but if master fails, the complete microgrid will be shutdown. A noiseresilient voltage observer is presented in [13] to take the mean voltage across the microgrid, this value is set to voltage regulator to produce a correction factor and adjust the present voltage set point which makes the voltage level preserved in microgrid as desired by tertiary control, here difficulty in cyber layer makes the system to lose its control. A multi-time scale droop based power management scheme is proposed in [14], but mode selection switch is there in it and its time-based control has some limitations in randomly changing irradiation patterns in solar PV power extraction. Above works are based on centralized control of microgrid, a decentralized method is proposed in [15], here various energy sources with fast and slow response are combined into a dc microgrid in a coordinated and flexible manner by shaping the converter output impedances in frequency domain according to their dynamic time scales, but this is also mode based adaptive droop control scheme. Intermittency in solar or wind requires battery storage system. If system rating is high, supported storage system cost also increases to meet the connected loads in the microgrid. A new configuration is proposed in [16] involving a series DC electric spring (series ES), photovoltaic (PV) panels, and a load to lessen the battery storage capacity of DC microgrids. But it includes tedious mathematical analysis and results are based on optimizing the parameters.

PV Storage independent microgrid is proposed in [17] where MPPT based droop control is explained. Active and reactive power reference based load sharing, conventional droop control and MPPT based droop control are proposed to extract power from DGs and send to load/grid, but here PV and storage are considered independently [18-20]. A multi-input transformer coupled bidirectional DC-DC converter is proposed in [21-24], here DC voltage regulation is taken care by Inverter in grid-connected mode. But in Islanded mode of operation, battery and DC-DC converter have to look out and PV is forced to operate in non-MPPT mode to maintain voltage regulation. Here, there is variation in dc link voltage for load changes and also a mode switching is used for reference input to MPPT voltage. In [23], a new control strategy for MPPT tracking is proposed for maintaining voltage regulation in addition to the maximum power point tracking (MPPT) in DC microgrids, which addresses the problem of mode switching. This control configuration avoids reconfiguration of control during PV mode switching, but here a separate DC-DC converter is used to aid battery to supply loads when PV output is reduced than load requirement. In [18], MPPT based droop control strategy is proposed to maintain load sharing between DGs, but here also two separate DC-DC converters are used.

In this paper, a transformer coupled bidirectional DC-DC converter topology [16] is considered with solar and battery as inputs and a modified $v-$ $d p / d v$ droop control strategy is implemented to avoid mode switching between MPPT and voltage regulation modes, and simultaneously does MPPT, battery SOC control, improve DC bus voltage regulation and under variations in load compared to earlier works. The control system is also worked as decentralized droop control to maintain load sharing between Distributed Generators in DC side of the inverter in islanded and grid-connected operating mode, thus this proposed control strategy is suitable for DC Microgrid. 


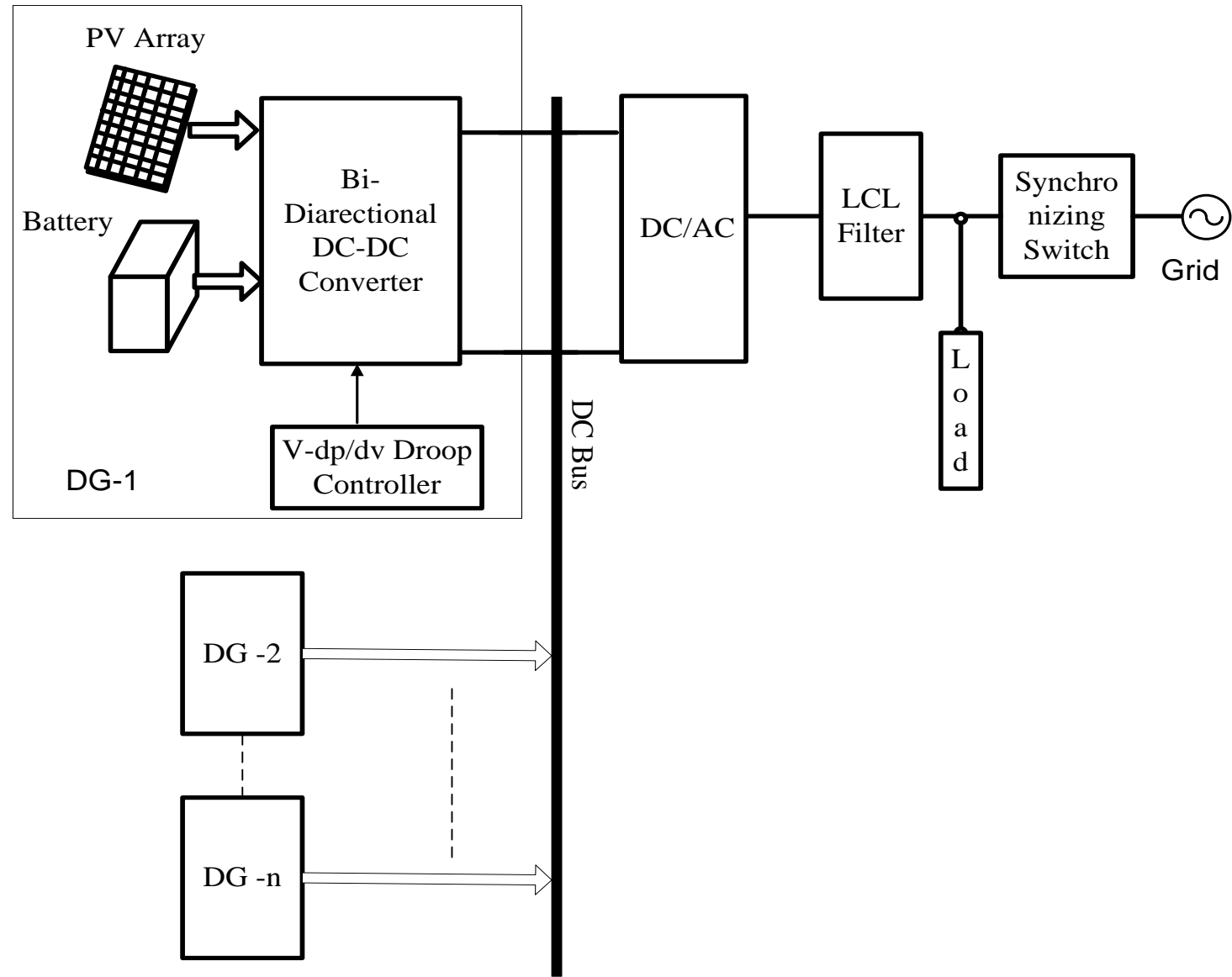

Figure. 1 Basic structure of Distributed Generator with PV system with Battery Backup for Islanded/Grid-connected operation

\section{System operation}

The proposed system consists of a PV array, a DC-DC converter to accommodate PV source, a battery and its control structure. Section 2.1 to 2.3 discusses PV array, converter operation, existing and modified MPPT control strategies, and section 3 illustrates the existing and proposed strategies.

\subsection{PV array}

The commonly accepted solar cell model is a one diode model [25]. When cell is exposed to light, the DC current is generated. The typical equivalent circuit of PV cell is shown in Fig. 2. PV arrays consist of 'Ns' series connected solar cells per string and ' $\mathrm{Np}$ ' such strings are connected in parallel which form a PV array. Thus, the equivalent circuit is represented by a current source parallel to an ideal diode. The mathematical model of PV arrays is given as

$$
I_{p h}=\left[I_{s c r}+k_{v}\left(v-v_{r}\right)\right] \frac{S}{1000}
$$

$$
\begin{aligned}
& I_{p v}=\left\{N_{p} I_{p h}-N_{p} I_{r s}\left\{\operatorname { e x p } \left(q \frac { v _ { d c } } { A k T } \left(v_{d c}+\right.\right.\right.\right. \\
& \left.\left.\left.\left.\frac{N_{s} R_{s e} I_{p v}}{N_{s}}\right)\right)\right\}\right\}-I_{r s h}
\end{aligned}
$$

Where $v_{r}$ is the cell reference temperature, $I_{s c r}$ is the short-circuit current of one PV cell at the reference temperature and irradiation level, and $K_{v}$ is a temperature coefficient. $v_{d c}$ is PV arrays voltage, $N_{p}$ and $N_{s}$ are the number of PV cells connected in parallel and in series respectively, $I_{p h}$ is the photocurrent of a single solar module which is proportional to both illumination and surface area, $I_{r s}$ is the saturation current of diode which is related to temperature, $k$ is Boltzmann constant $\left(1.38 \times 10^{-23}\right.$ $\mathrm{J} / \mathrm{K}), q$ is electric charge $\left(1.6 \times 10^{-19} \mathrm{C}\right), \mathrm{T}$ is operating temperature (in kelvins), A is P-N junction ideal factor. $R_{S}$ is series resistance of the single solar module, and $I_{r s h}$ is the current flowing through the shunt resistance. Ignoring the power absorbed by the inductance and the resistance of the Voltage source converter (VSC) interface, the generally accepted 
solar cell model is a single diode model of the solar cell to model the Kyocera KC200GT solar array.

\subsection{Principle of operation of converter}

A dual input DC-DC converter is used for simultaneous maximum power point tracking control (MPPT) of a solar PV generation system consisting of photovoltaic (PV) panels and battery, operation and control of this topology is given in [21, 22], In this paper DC-DC converter is shown in Fig. 3, with Solar and battery inputs is considered for power transfer from PV and Battery to load/Grid and its working is explained in three modes.

\section{Mode I:}

a) Operation of the converter when inductor current is positive: when $S W 1$ is turned on, the PV array voltage $v_{p v}$ is appeared across inductor $L$ and the inductor current, $i_{L}$ increases. During this period, the voltage appeared across the primary winding of the transformer is,

$$
V_{p r i}=\left(V_{b a t t}+V_{p v}-V_{c 1}\right)
$$

Wherein $v_{b}$ is the battery voltage and $v_{c 1}$ is the voltage across the capacitor, $C 1$. Hence the primary current of the transformer, $i_{p r i}$ increases and the capacitor, $\mathrm{Cl}$ gets charged. The current flowing through the secondary winding of the transformer $i_{\text {sec }}$ also increases. The diode, D3 is forward biased and the capacitor, $C 2$ gets charged. If ' $n$ ' is the turn ratio of the transformer. The voltage across $C 2$ is given by,

$$
V_{c 2}=n\left(v_{b a t t}+v_{p v}-v_{c 1}\right)
$$

b) Operation of the converter when inductor current is negative: This mode begins when $S W l$ is turned on and $S W 2$ is turned off. At the time of starting, $i_{L}$ is negative and, $i_{p r i}$ is zero. Hence the diode $D l$ starts

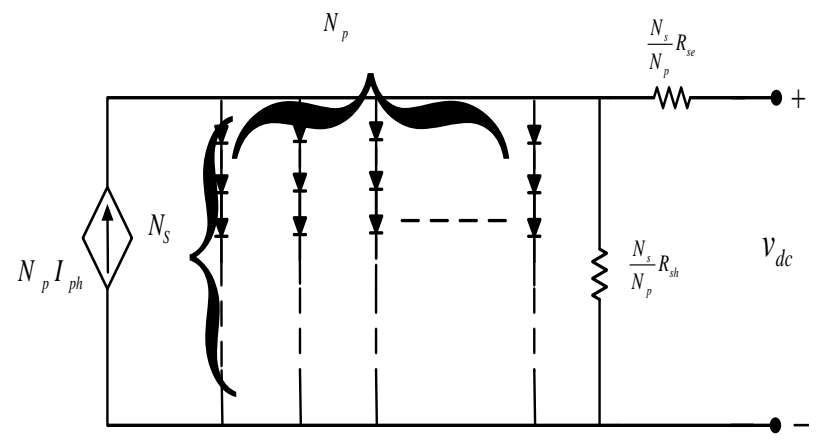

Figure. 2 Equivalent circuit of PV Cell

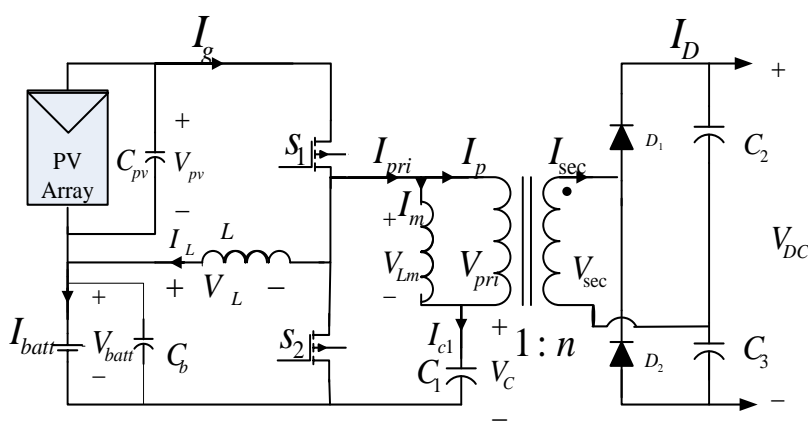

Figure. 3 Circuit diagram of DC-DC converter with battery backup

-conducting. The rest of the operation is same as that of mode I. This mode continues till $i_{\text {pri }}$ becomes equal to $\left(-i_{L}\right)$.

Mode II:

(a) Operation of the converter when inductor current is positive: This mode begins when SWI is off and $S W 2$ is on. At the starting, $i_{L}$ is positive and as $S W 1$ is off $i_{\text {pri }}$ is zero. Since $i_{L}>i_{\text {pri }}$, the diode $D 2$ starts conducting. The voltage appeared across $L$ is, $v_{L}=$ $-v_{\text {batt }}$ and hence $i_{L}$ starts decreasing. The voltage appeared across the primary winding of the transformer is, $v_{p r i}=v_{c 1}$ and hence $i_{p r i}$ becomes negative and starts falling thereby discharging $C l$.

The current flowing through the secondary winding of the transformer $i_{\text {sec }}$ reverses and the diode $D 4$ gets on. The capacitor $C 3$ is getting charged and the voltage across $C 3$ is $v_{c 3}=n v_{c 1}$. During this mode, $i_{L}>\left(-i_{p r i}\right)$ and diode $D 2$ is forward biased. This mode continues till $i_{L}$ becomes equal to $-i_{\text {pri }}$.

(b) Operation of the converter when inductor current is negative: When $i_{p r i}$ becomes greater than $-i_{L}$ the diode $D l$ is reverse biased and the switch, $S W 1$ starts conducting. The rest of the operation is same as that of mode I.

\section{Mode III:}

(a) Operation of the converter when inductor current is positive: When $i_{L}$ becomes smaller than $-i_{\text {pri }}$, the diode $D 2$ is reverse biased and the switch, $S W 2$ starts conducting. The rest of the operation remains the same as that of mode II.

(b) Operation of the converter when inductor current is negative: This mode begins when $S W 1$ is turned off and $S W 2$ is turned on. During this mode, both $i_{L}$ and $i_{p r i}$ are negative and the switch $S W 2$ conducts. The negative current in the primary winding of the transformer results in negative current in the secondary winding of the transformer. Hence the 
diode $D 4$ is forward biased and the capacitor $C 3$ gets charged. During operation in this mode, $v_{L}=$ $-v_{\text {batt }}, v_{p r i}=-v_{c 1}$ and $v_{c 3}=\mathrm{n} v_{c 1}$. The voltage, $v_{L}$ across the inductor, $L$ can be expressed as mentioned in the Eq. (4)

$$
V_{L}=V_{p v}
$$

When the switch $S W 1$ is ON

$$
V_{L}=V_{\text {batt }}
$$

\section{When the switch $S W 1$ is OFF}

Therefore, the average voltage drop across the inductor is,

$$
V_{L}=D V_{p v}-(1-D) V_{b a t t}
$$

Where in $D$ is the duty ratio of the switch $S W 1$. Equating average

$$
V_{p v}=\left(\frac{1-D}{D}\right) V_{b a t t}
$$

From Eq. (6) it can be inferred that the PV voltage can be controlled by manipulating $D$ as battery voltage $v_{\text {batt }}$ can be assumed to be a stiff source. Therefore, MPPT operation of PV array can be achieved through a proper manipulation $D$. The average output voltage of the above circuit is, $v_{d c}$ is given by,

$$
V_{d c}=\left(V_{c 2}+V_{c 3}\right)
$$

\subsection{MPPT Control}

\subsubsection{Existing MPPT control}

In previous work [6], when battery is fully charged and PV power generation is more than load power requirement, $\mathrm{PV}$ is forced to operate in non MPPT mode where mode switching, i.e., reference voltage to MPPT is changed to maintain voltage regulation, thus, there's a switching between MPPT to non-MPPT mode. The region of operation of this MPPT is in and around maximum power point based on perturb and observe algorithm, i.e., the operating voltage is changing around actual $V_{M P P}$ (voltage at maximum power point) and the operating region on PV characteristics is as shown in Fig. 4 (a). The proposed control strategy unifies DC bus voltage control, Maximum power point (MPPT) control and battery charging/discharging, using same converter and in view of the same configuration. In this, the modified MPPT control strategy [6,7] is used and operating region of this MPPT technique is as shown in Fig. 4(b). The configuration is more realistic for residential DC microgrid application as every house has its own solar PV and battery installation and they need to connect to a centralized DC bus to feed its generated power, and if any DC loads exist with them they connect directly to DC bus, and for ac loads they usually connect it to the utility grid, DC appliances (loads) utilization reduces power losses in utility grid, also DC microgrid can feed customers in Islanded mode when there is a fault on AC side, thus, uninterrupted power is supplied to the customer. Decentralized control of DGs can be possible by droop control of DC-DC converters connected to DCbus, based on the m-value specified for each DG, the load is shared between different DGs as per the droop coefficient ' $m$ ', expressions for how it shares the load is discussed in section 2.3.2.

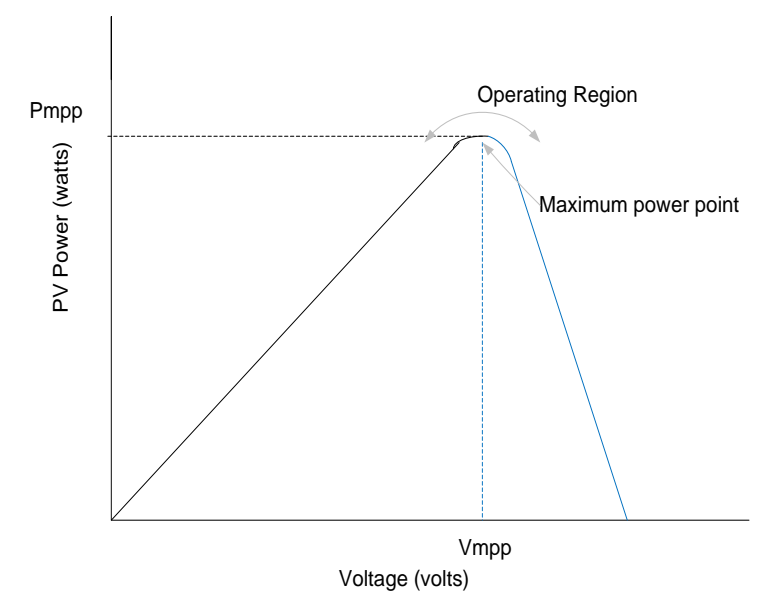

(a)

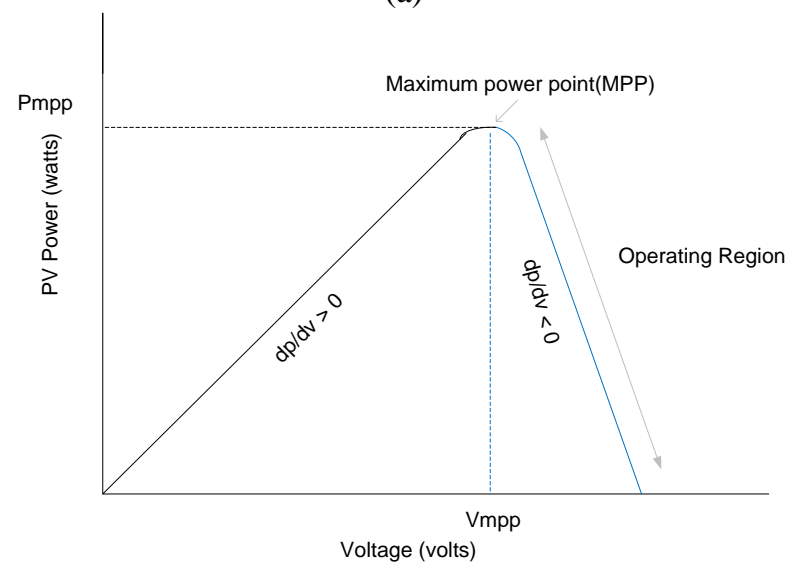

(b)

Figure. 4 Operating voltage: (a) conventional MPPT and (b) modified MPPT 


\subsubsection{Modified MPPT control}

In this control technique, MPP is achieved by controlling the operating point with respect to the slope of the right side portion of PV curve which has a negative slope region on PV characteristics. The slope of the curve is changing from MPP (maximum power point) to Voltage axis where power is zero. Thus, if the slope is chosen as the control variable, by changing slope, the operating point can be changed, in this way MPP can be reached, at the maximum power point, the slope becomes zero $(d p / d v=0)$.

Proposed control strategy caters following benefits:

- PV source regulates DC bus voltage automatically and takes part in load sharing along with other PV sources.
- PV source pumps maximum available power to microgrid up till DC microgrid is grid (utility) connected or as long as there is a sufficient load connected when it is in islanded operation.

- The PV sources can export its maximum available power to the microgrid as long as the DC-microgrid is grid-connected or there is sufficient load when it is islanded.

- No need of Mode transition of controller during PV operation.

- As Droop control is decentralized in nature, no communication system is required between DGs (Distributed generators)

- $d p / d v$ Value does not change with Irradiation and Temperature.

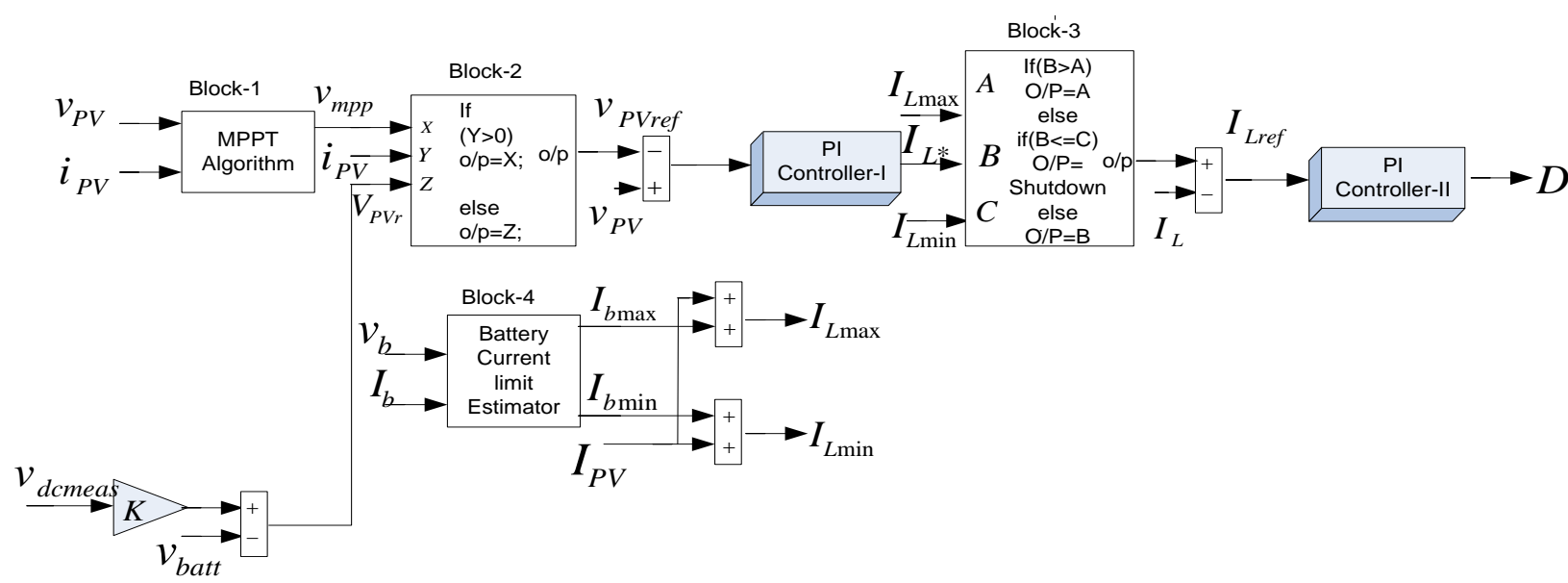

(a)
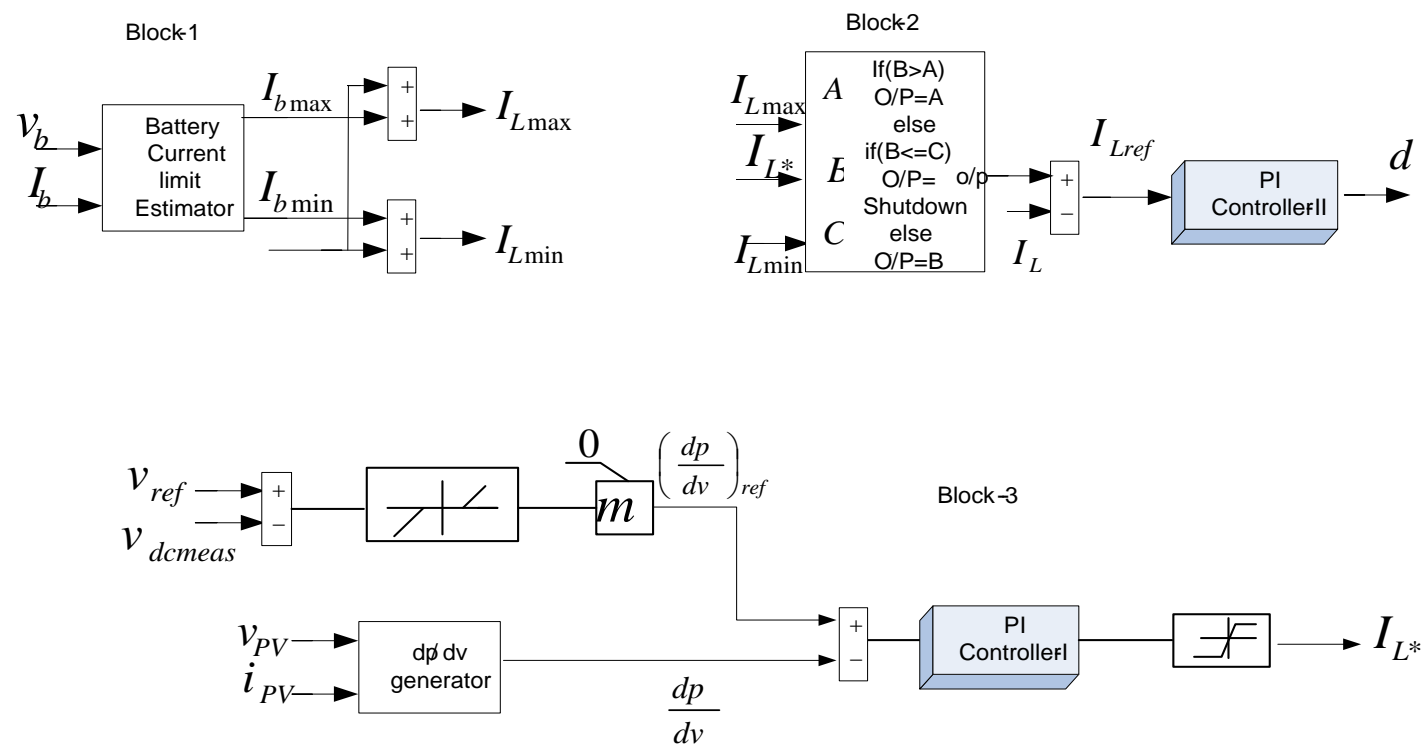

(b)

Figure. 5 (a) existing control structure of transformer coupled DC-DC converter and (b) existing control structure of transformer coupled DC-DC converter 


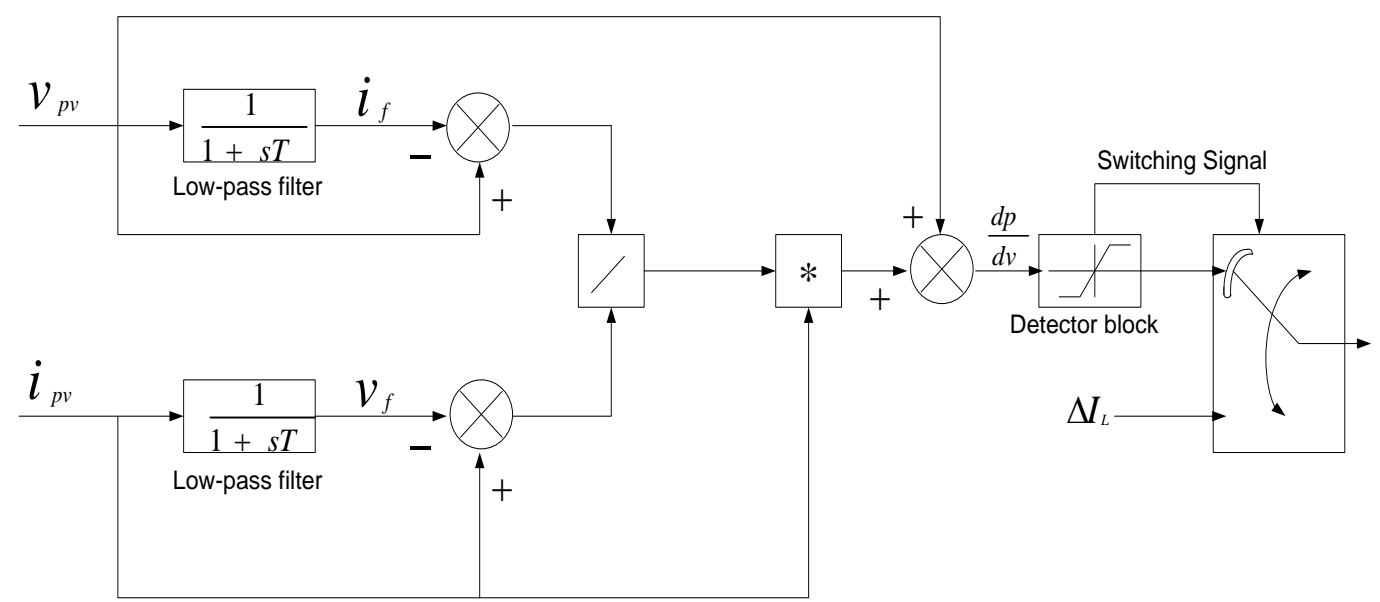

Figure. 6 Existing control structure of transformer coupled DC-DC converter

\section{Control strategy}

In this section, the control structure of PV System is explained in detail. First subsection explains the control of DC-DC converter switches $S W 1$ and $S W 2$, which are complementary in nature. Second subsection discusses control of inverter in such a way that its output voltage and frequency is regulated as per load requirements. It is controlled by PWM control based on anti-islanding control, it will work on Islanded or grid-connected mode.

Here, classical P\&O based MPPT in Fig.5 (a) is replaced by coordinated $d p / d v$ based MPPT block3 in Fig.5 (b) which coordinates MPPT and DC bus voltage regulation in a seamless way of switching. Two DGs are considered to emphasize load sharing between DGs.

Fig.5 (b) shows a modified control strategy, in which working of $d p / d v$ control technique is explained below.

$$
\frac{d p}{d v}=v_{p v} \frac{d i}{d v}+i_{p v}=v_{p v}\left(\frac{i_{p v}-i_{f}}{v_{p v}-v_{f}}\right)
$$

The above expression is implemented in Simulink as shown in Fig6, where ' $i_{f}$ ' and $v_{f}$ are filtered values of ' $i_{p v}$ ' and $v_{p v}$, there should be limitation for $d p / d v$ to avoid overstepping, a detector provided, which block the $d p / d v$ calculation, when overstepped and adds' $\Delta I_{L}$ ' to ' $I_{L}$ '. The value ' $m$ ' decides the power sharing between DGs, but as PV-curve is nonlinear, it is to be linearized by line joining Maximum power point (MPP) and zero power point (ZPP) as show in Fig. 7 [23]. Here hat in Eq. (10) and Solid line of Fig. 7 represents linearizing PV power characteristics $V-$ $d p / d v$ controller as shown in Fig. 5(b) multiplies the droop coefficient ' $m$ ' with difference between $\mathrm{dc}$ bus voltage $V_{d c}$ and its reference value $V_{d c_{-} r e f}$ to produce $(d p / d v)^{r e f}$ for $d p / d v$ regulator as shown below.

Where $(d p / d v)^{*}$ represents the nominal value of $d p / d v$ i.e., slope of PV curve and this value is set to ZERO to unify Maximum Power Point Tracking (MPPT) and voltage regulation control with same controller.

The linearized model of the a given PV based $i^{\text {th }}$ DG is given as

$$
\begin{aligned}
& \frac{d p^{r e f}}{d v}=\frac{d p^{*}}{d v}-m\left(v_{d c}-v_{d c_{-} r e f}\right) \\
& \hat{P}_{p v_{-} i}=\hat{f}\left(\frac{d p}{d v_{i}}\right)=\frac{P_{\max _{\_} i}}{y\left(v_{p v_{-} o c i}\right)} \frac{d p}{d v_{i}}+P_{\max _{-} i}
\end{aligned}
$$

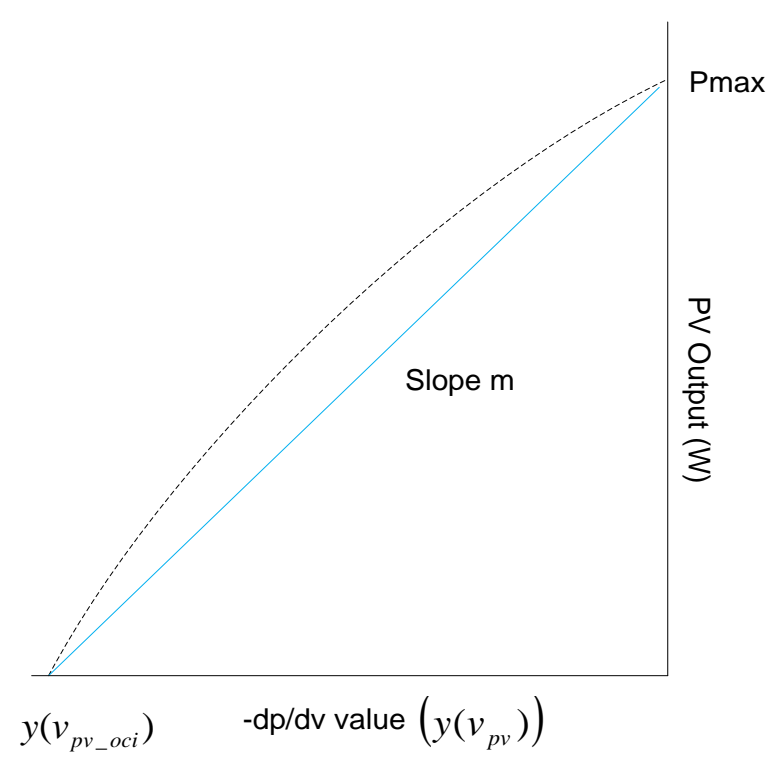

Figure. $7 P_{p v}-d p / d v$ and $\widehat{\mathrm{P}}_{\mathrm{pv}}-d p / d v$ curves for $\mathrm{PV}$ panel 
Subscript ' $i$ ' represents $i^{\text {th }}$ DG source. Thus load sharing droop parameter $\mathrm{m}$ can be identified as

$$
\frac{\hat{P}_{p v_{\_} 1}}{\hat{P}_{p v_{-} i}}=\frac{\frac{P_{\max \_1} d p}{y\left(v_{p v_{o c 1}}\right) d v_{1}}+P_{\text {max } \_1}}{\frac{P_{\max i} i d p}{y\left(v_{p v_{o c i}}\right) d v_{i}}+P_{\text {max } \_i}}
$$

But Eq. (12) ' $d p / d v$ ' can be represented as $-m_{i} \Delta V$, Where, $\Delta V=V_{d c}-V_{d c_{r e f}}, P_{\text {max }_{-} i}$ represents the maximum power generated by $i^{\text {th }} \mathrm{DG}$

Substituting the above value in Eq. (12) and rewritten the same as follows,

$$
\frac{\hat{P}_{p v_{-} 1}}{\hat{P}_{p v_{-} i}}=\frac{\frac{P_{\max \_} 1}{y\left(v_{p v_{O C 1}}\right)} m_{1} \cdot \Delta V+P_{\max \_1}}{\frac{P_{\max i} i}{y\left(v_{p v_{o c i}}\right)} m_{i} \cdot \Delta V+P_{\max _{-} i}}
$$

The main purpose of droop controller is proportional load sharing as shown below,

$$
\frac{\widehat{\mathrm{P}}_{\mathrm{pv \_ 1}}}{\widehat{\mathrm{P}}_{\mathrm{pv \_ i}}}=\frac{\mathrm{P}_{\max \_1}}{\mathrm{P}_{\max \_\mathrm{i}}}
$$

Substituting Eq. (16) in Eq. (15) will give the expression of $m_{i}$ which is slope of PV curve (or) droop control parameter responsible for proportional load sharing between different DGs,

$$
m_{i}=\frac{y_{i}\left(v_{p v_{-} o c i}\right)}{v_{d c_{-} \text {max }}-v_{d c_{-} r e f}}
$$

Where, $V_{d c_{-} \max }, V_{d c_{-} \text {ref }}$ are the upper voltage limit and reference voltages of the DC microgrid respectively. The expression for $i_{p v}$ is given in Eq. (1), multiplying it with $V_{p v}$ to get the expression for PV power given in Eq. (11)

$$
\begin{aligned}
& p_{p v}=v_{p v} i_{p v} \\
& y_{i}\left(v_{p v i}\right)=\frac{d p}{d v_{p v}} \\
&=i_{p v}+v_{p v} \frac{d i_{p v}}{d v_{p v}}
\end{aligned}
$$

$Y_{i}\left(V_{p v_{-} o c i}\right)$, is the value of $d p / d v$ when PV voltage reaches its nominal open circuit value of $i^{\text {th }}$ DG, i.e. $\left(v_{p v}=v_{o c, n}\right)$, where suffix ' $n$ ' represents nominal value.

$$
y_{i}\left(v_{p v_{o c i}}\right)=N_{p i} I_{s c, n_{i}}\left(\frac{G}{G_{n}}-1-\frac{V_{o c, n_{i}}}{\alpha v_{t}}\right)
$$

Here, $p_{p v}$ is the power generated by solar PV panel from which $d p / d v$ i.e. $y_{i}\left(v_{p v i}\right)$ is calculated, given in Eq. (17), solve for $d p / d v$ and substituting $v_{p v}=$ $v_{o c, n}$, to get Eq. (18). ' $G$ ' is the irradiance at a given point of time and ' $G_{n}$ ' ' is the nominal irradiation, generally $1000 \mathrm{w} / \mathrm{m}^{2}$.

\section{Case Study:}

Case-I: If $P_{\text {mppt }}>P_{\text {load }}$ i.e., PV panel delivers power which is in operation at MPPT is more than load required, the surplus power $P_{m p p t}-P_{\text {load }}$ is absorbed by the battery, then total power delivered by PV panel $P_{\text {mppt }}=P_{\text {load }}+P_{\text {batt }}$, where $P_{\text {batt }}$ is the power absorbed by the battery, from the above decentralized control structure each DG, $I_{L}{ }^{*}$ of converters become positive representing battery is in charging mode. In this case, the DC bus voltage is maintained at reference value and PV operating at MPP which is similar to grid-connected operation, here, $d p / d v$ regulator in Fig. 6(b) gives ZERO reference to operate PV source work in MPP.

Case-II: If $P_{\text {mppt }}>P_{\text {load }}$, and battery reached its maximum charging limit $P_{b \max }$, as battery should not be overcharged, the PV panel is forced to operate at reduced power i.e., in non-MPPT mode in order to maintain voltage regulation at DC-bus. But here battery no more able to store excess power, this excess power charges the DC link capacitors thus voltage across DC bus increases more than $v_{d c_{-} r e f}$, and subsequently the droop controller shown in block-3 of Fig. 8 generated negative $d p / d v$ command to render PV source to operate in such a way, so as to balance generation and load. If once load increases in voltage regulation mode, the droop controller makes PV operating point move back towards MPP.

Case-III: Here a decentralized control strategy is applied i.e., two DGs of similar rating as shown in Fig.4 are connected parallel with its individual control strategies across the load whose rating is $1 \mathrm{KW}$. A sudden change in load causes change in load shared by each generator is almost similar. It is the responsibility of controllers associated with converter to select the mode of operation and logical decision making Block-2. Block-1 is used to process the data regarding the availability of PV power and SOC of battery and necessary signals are generated for safe running of DC-DC converter.

Case-IV: In this case, DG shifts its operation from Islanded to Grid-connected mode and a sudden load change causes a corresponding change in grid current, 
but inverter side current remains unaltered, means, any changes in load can be supported by grid and PV always operate in MPPT mode in grid-connected case.

\section{Simulated performance}

The Proposed Isolated PV system is simulated on MATLAB/SIMULINK platform in order to determine the feasibility of the control scheme. PV module parameters are shown in Table 1, and PV panel has two strings with each string taking one PV module connected panels. At $1000 \mathrm{~W} / \mathrm{m}$ and $25 \mathrm{C}$ (STC), Maximum Power developed by single module is $250 \mathrm{~W}$.so, the maximum power of the PV power delivered by PV panel at STC is $525 W$.i.e. $2 X 34.5$ $X 7.4=525 \mathrm{~W}$.

The simulated performance obtained under various test cases is presented in this section. The DC-DC converter inverter, battery and load parameters are specified in Table 2. The cases (I-IV) of operation discussed in control strategy are simulated and results are shown below, for the shutdown case which happens for standalone systems only. This case is not discussed here, but this can be done by withdrawing pulses to $S W 1$ and $S W 2$ in Fig. 4(b).

\section{Simulated Results for the above case study:}

i) $P_{\text {load }}<P_{\text {mppt }}$ : A load of $480 \mathrm{~W}$ is maintained on AC side, PV power with MPPT is obtained as $500 \mathrm{~W}$, and remaining $20 \mathrm{~W}$ is delivered to battery. Here battery current $i_{\text {bmin }}<i_{b}<i_{\text {bmax }}$, battery limits are between $I A$ and $3 A$ for maximum and minimum currents to maintain battery state of charge (SOC) between $20 \%$ and $90 \%$.

ii) $P_{\text {load }}<P_{\text {mppt }}$ : A load of $480 \mathrm{~W}$ is maintained on AC side, $\mathrm{PV}$ power with MPPT is obtained as $500 \mathrm{~W}$, but at $0.4 \mathrm{sec}$ load is changed from $480 \mathrm{~W}$ to $300 \mathrm{~W}$, and battery current is $i_{b}>i_{\text {bmax }}$.In this work $i_{\text {bmax }}$ set to $0.7 \mathrm{~A}$ thus battery cannot draw further current, PV is forced to operate at non-MPPT mode and feeding reduced power to the load and this will continue up to $0.7 \mathrm{sec}$ and again the load is raised to $480 \mathrm{~W}$. Thus Changes in PV outputs, battery and DC bus voltage is shown in the following figures.

Here change in DC link voltage in Fig. 10 is minimum, which indicates that controller has worked to operate at voltage regulation mode when there is a change in load and battery is unable to absorb excess power delivered by PV when operated under MPPT. Here, waveforms are started with delay at zero as the mean values are considered for plots. Voltage regulation improvement comparison of existing
Table 1. PV panel Parameters at STC

\begin{tabular}{|c|c|}
\hline PV Panel Parameters & Value \\
\hline$N$ & 28 \\
\hline$N_{s}, N_{p}$ & 1,2 \\
\hline$V_{M P P}$ & $34.5 \mathrm{~V}$ \\
\hline$I_{M P P}$ & $7.4 \mathrm{~A}$ \\
\hline$P_{M P P}$ & $525 \mathrm{~W}$ \\
\hline$V_{O C}$ & $40 \mathrm{~V}$ \\
\hline$I_{S C}$ & $8.7 \mathrm{~A}$ \\
\hline
\end{tabular}

Table 2. Standalone System Parameters

\begin{tabular}{|l|l|}
\hline Parameter & Value \\
\hline power rating & 500VA \\
\hline Transformer turns ratio, $\mathrm{n}$ & 6 \\
\hline Capacitors & $\mathrm{C}_{\mathrm{pv}}=2000 \mu \mathrm{F}$, \\
& $\mathrm{C}_{\mathrm{b}}=1000 \mu \mathrm{F}$ \\
& $\mathrm{C}_{\mathrm{f}}=8 \mu \mathrm{F}$, \\
& $\mathrm{C}_{1}=470 \mu \mathrm{F}$, \\
& $\mathrm{C}_{2}=\mathrm{C}_{3}=1000 \mu \mathrm{F}$ \\
\hline Inductors & $\mathrm{L}_{\mathrm{b}}=1 \mathrm{mH}, \mathrm{L}=3 \mathrm{mH}$, \\
& $\mathrm{L}_{\mathrm{f}}=2.5 \mathrm{mH}$ \\
\hline Switching frequency, & $\mathrm{Fs}_{2}=15 \mathrm{kHz}$ \\
\hline MPPT & $\mathrm{V}-\mathrm{dp} / \mathrm{dv}$ power point \\
& tracking \\
\hline Battery rating & $36 \mathrm{~V}, 7 \mathrm{Ah}$ \\
\hline
\end{tabular}

Table 3. Comparison between existing and proposed control strategies.

\begin{tabular}{|l|l|l|}
\hline Parameter & $\begin{array}{l}\text { Modified } \\
\text { Method }\end{array}$ & $\begin{array}{l}\text { Existing } \\
\text { Method }\end{array}$ \\
\hline Reference Voltage & $400 \mathrm{~V}$ & $410 \mathrm{~V}$ \\
\hline $\begin{array}{l}\text { Change in Voltage } \\
\text { due to load change }\end{array}$ & $398-403 \mathrm{~V}$ & $405-430 \mathrm{~V}$ \\
\hline Overshoot & Absent & present \\
\hline
\end{tabular}

control strategy and new control strategy is shown in Fig. 4(a) and 4(b) respectively are shown in the Fig. 14 , which depicts the contribution of this work. Fig.13 shows the output voltage and current at load in Islanded mode operation, and power delivered to the load is shown in Fig. 12 and Input PV power change in Islanded mode for load change is shown in Fig.16. Load change for this time is created between $0.4 \mathrm{sec}$ to $0.6 \mathrm{sec}$. In Existing method, reference voltage is given to DC reference value and is maintained at $410 \mathrm{~V}$, when load is changed at $0.4 \mathrm{sec}$, its voltage is raised to $430 \mathrm{~V}$ i.e., between 0.4 to $0.6 \mathrm{sec}$ whereas proposed control strategy controls DC link voltage accurately near to its reference value. 
Detailed comparison analysis of existing and proposed control strategies are specified in Table 3. iii) Load sharing between two DGs are shown in Fig. 18 by considering different droop coefficients and its details are shown in Table 4. Considering two DGs with decentralized control sharing a load of
$1000 \mathrm{~W}$ with a total load current of $1000 / 230=4.34 \mathrm{~A}$ (considering R-Load), rating of individual distributed generator shown in Fig. 3 is $500 \mathrm{~W}$, assuming droop coefficient of DG i.e., $m l=50$, and for DG2 is $m 2=150$, thus the load is shared as per droop values.
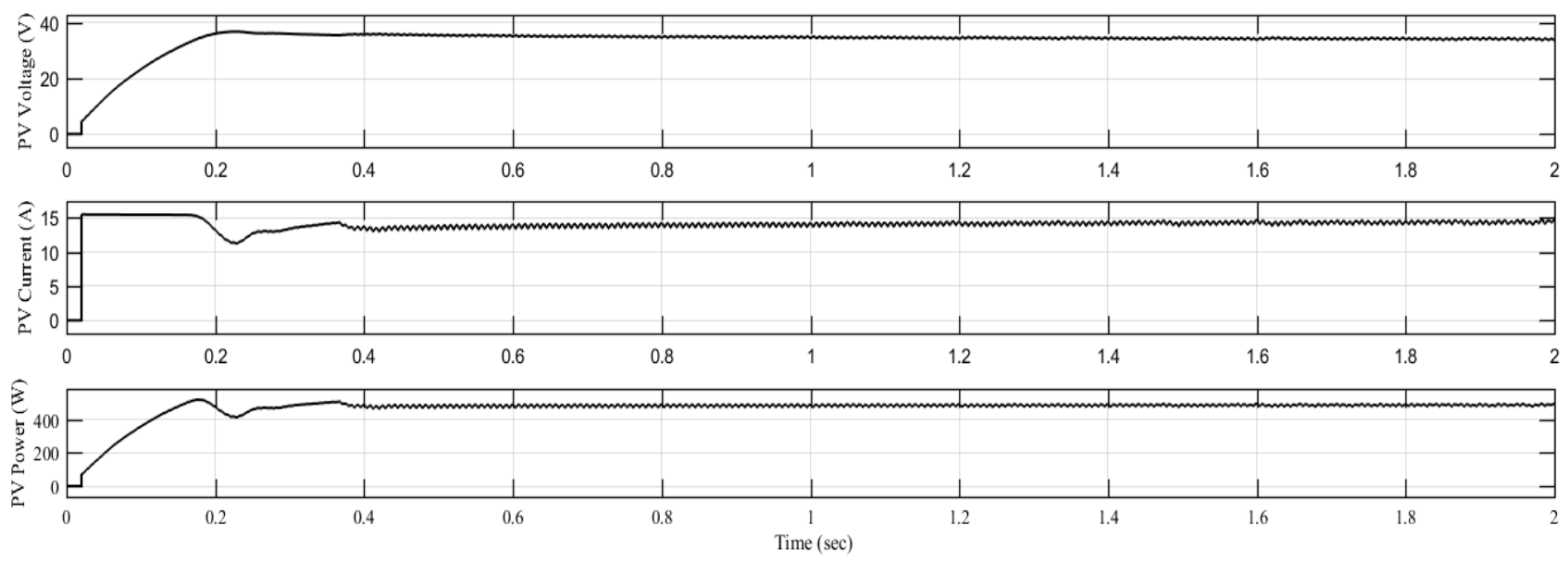

Figure. $8 \mathrm{PV}$ voltage current and power with load maintained constant in Islanded operation
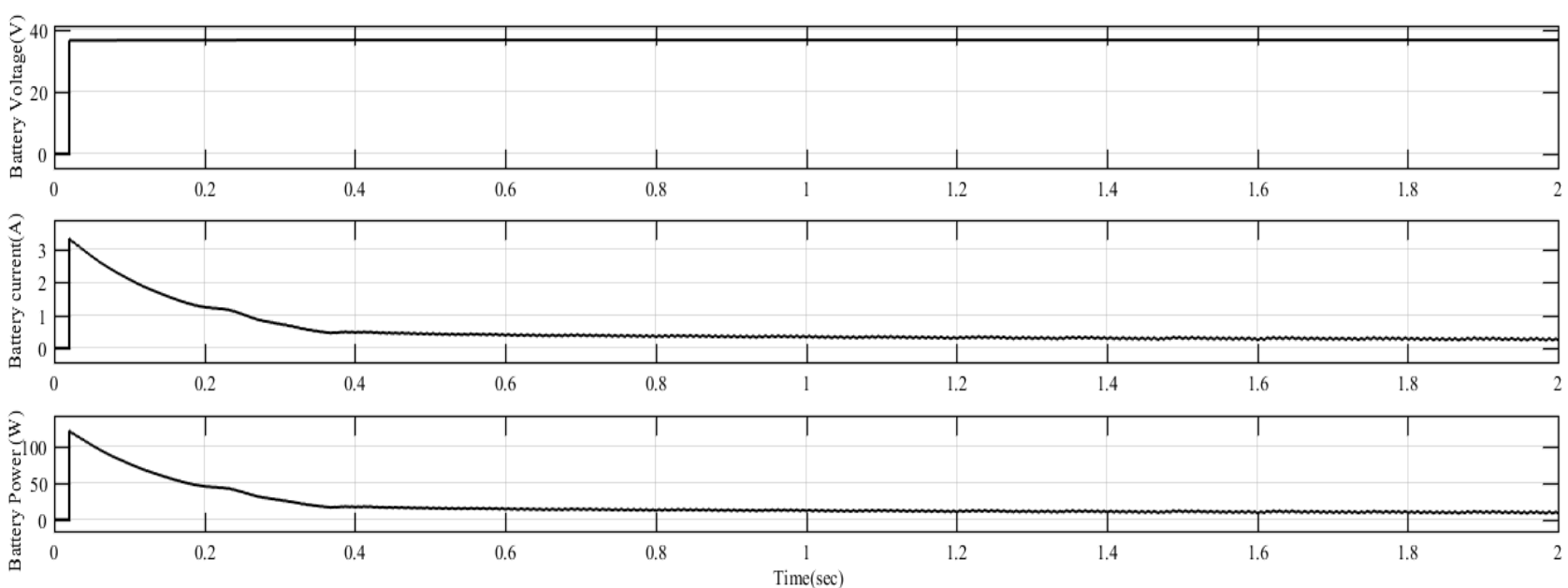

Figure. 9 Battery voltage current and power with load maintained constant in Islanded mode

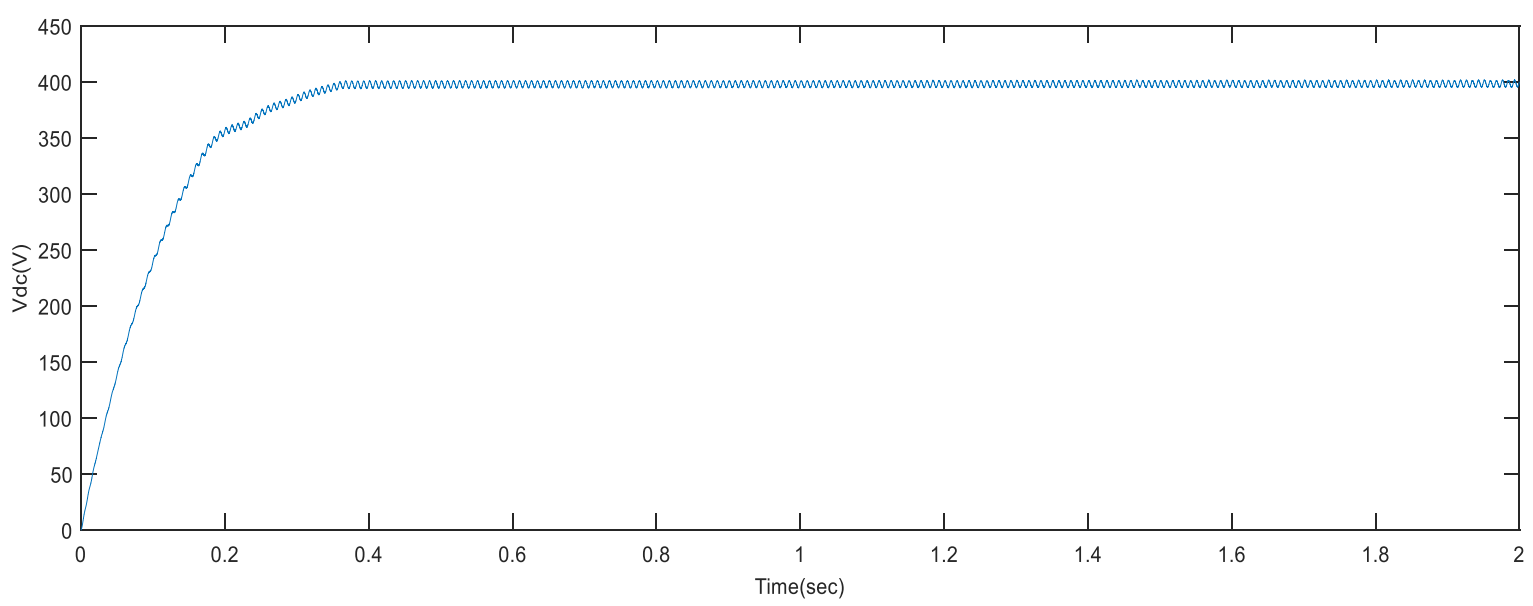

Figure. 10 DC bus voltage with load maintained constant in islanded operation 


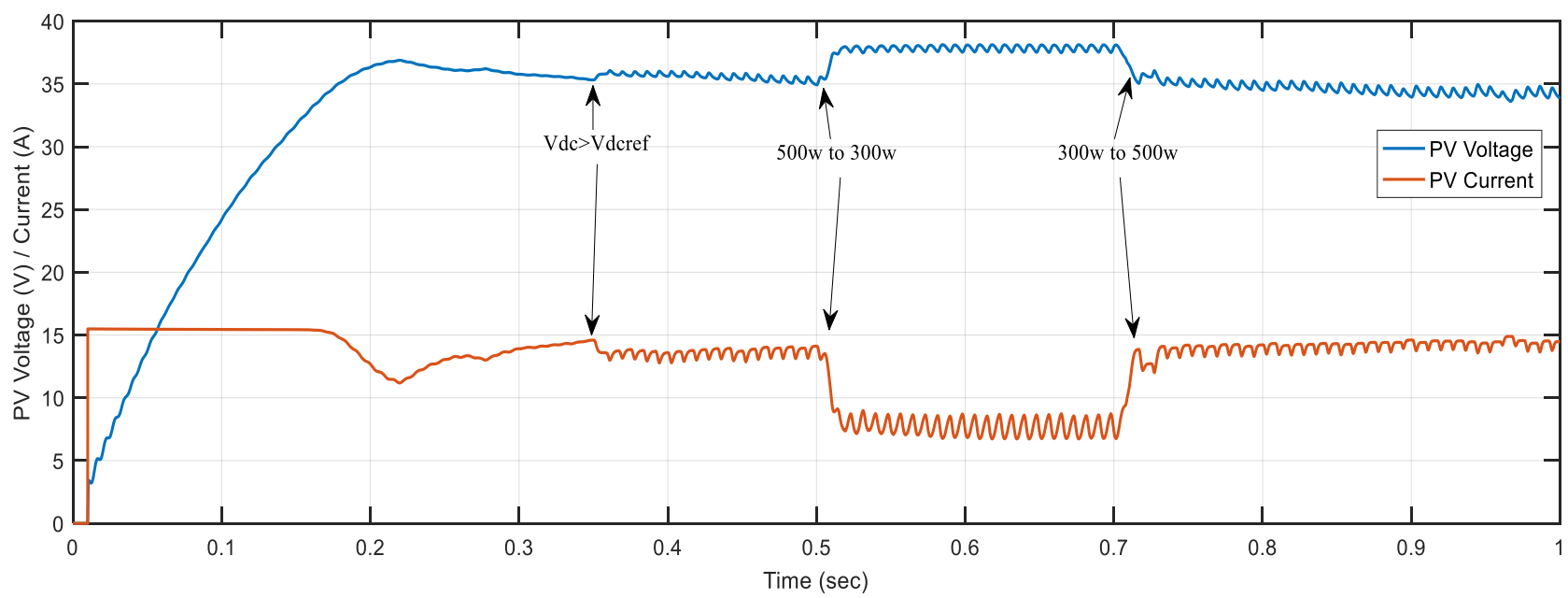

Figure. $11 \mathrm{PV}$ voltage and current waveforms for load change

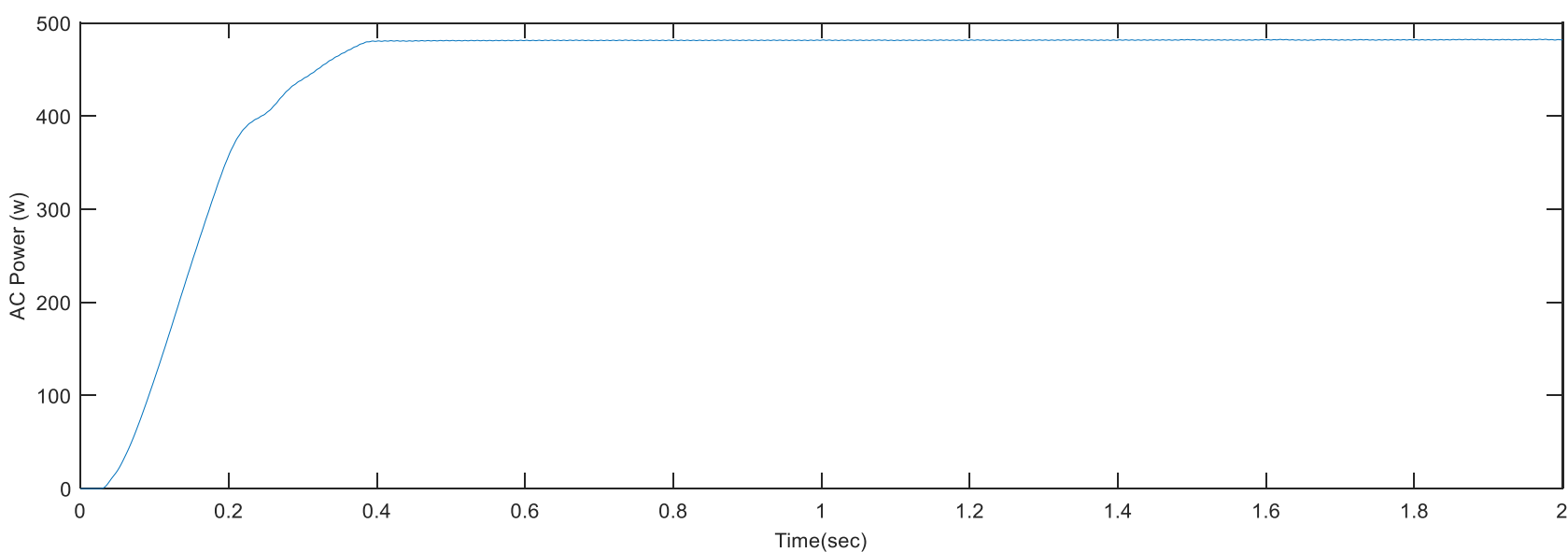

Figure. 12 Load power output waveform

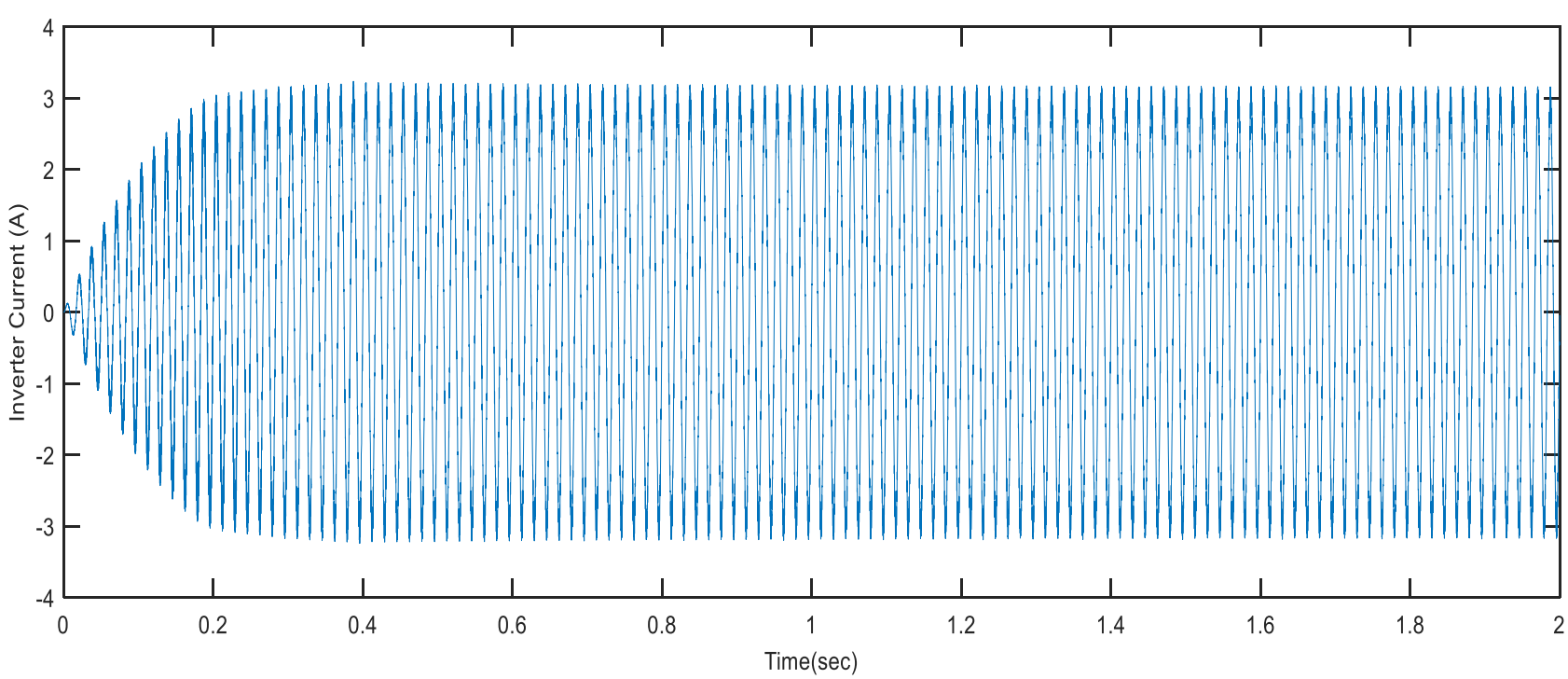

(a) 


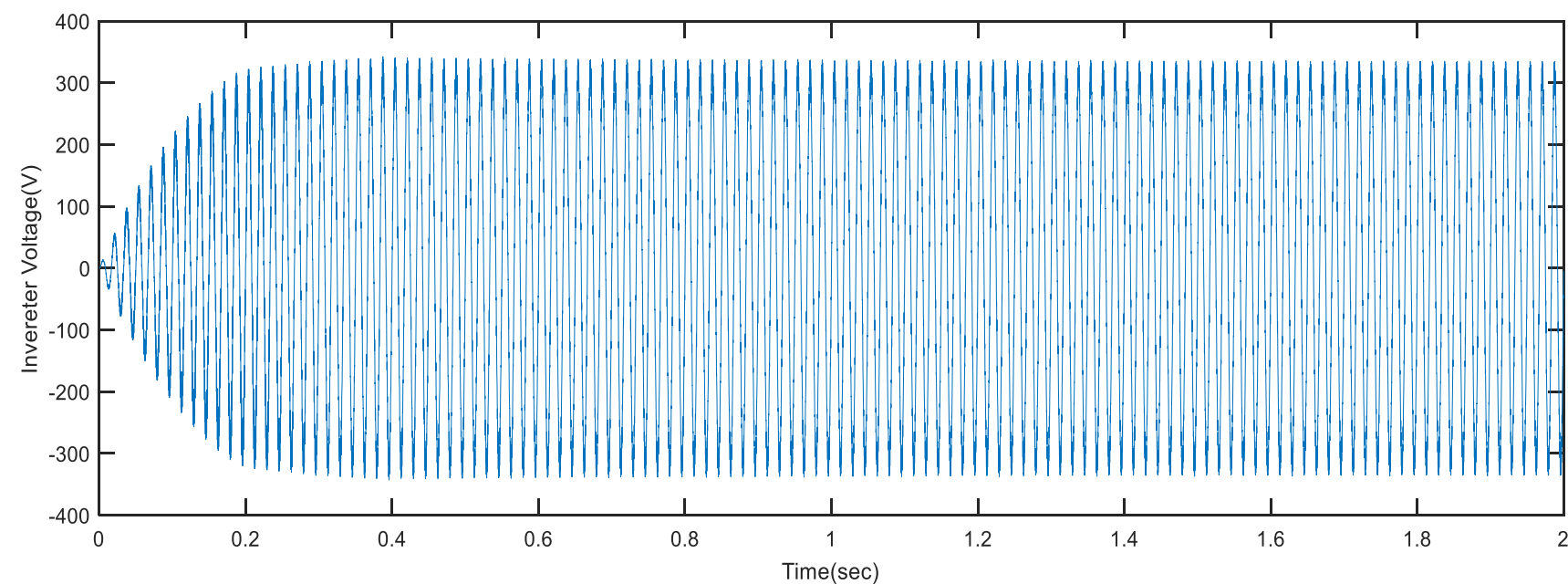

(b)

Figure.13 AC side voltage and current waveforms

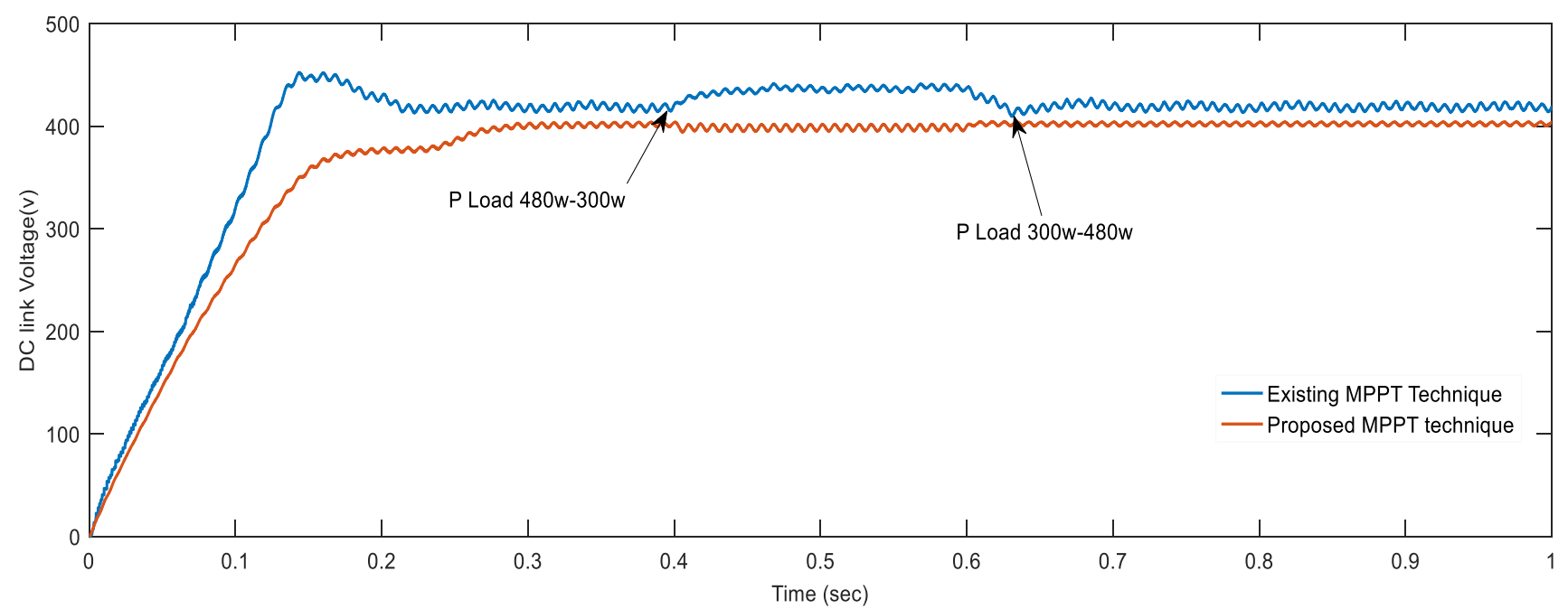

Figure. 14 DC link voltage when load is suddenly changed from 480 to 300 change in PV power for change in load with existing and new MPPT control strategy

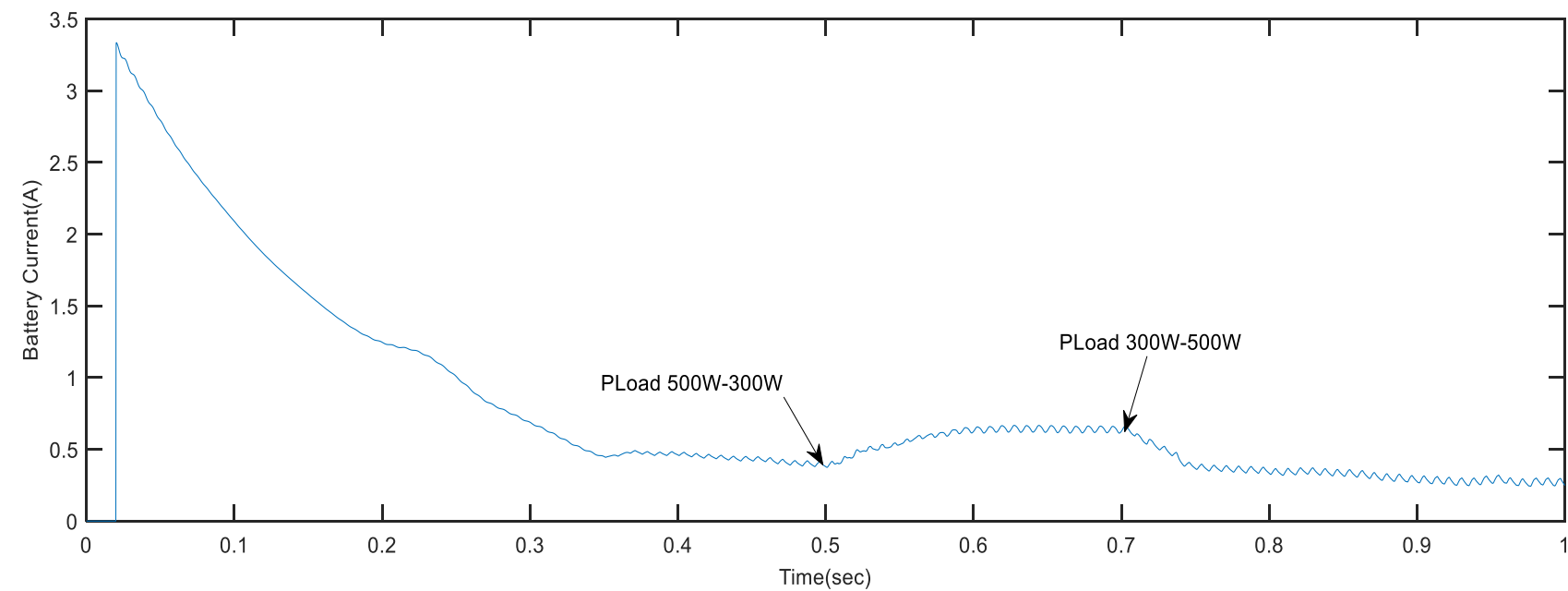

Figure. 15 Battery current when load is suddenly changed from 480 at $0.4 \mathrm{sec}$ to 300 at $0.7 \mathrm{sec}$ in islanded operation. 


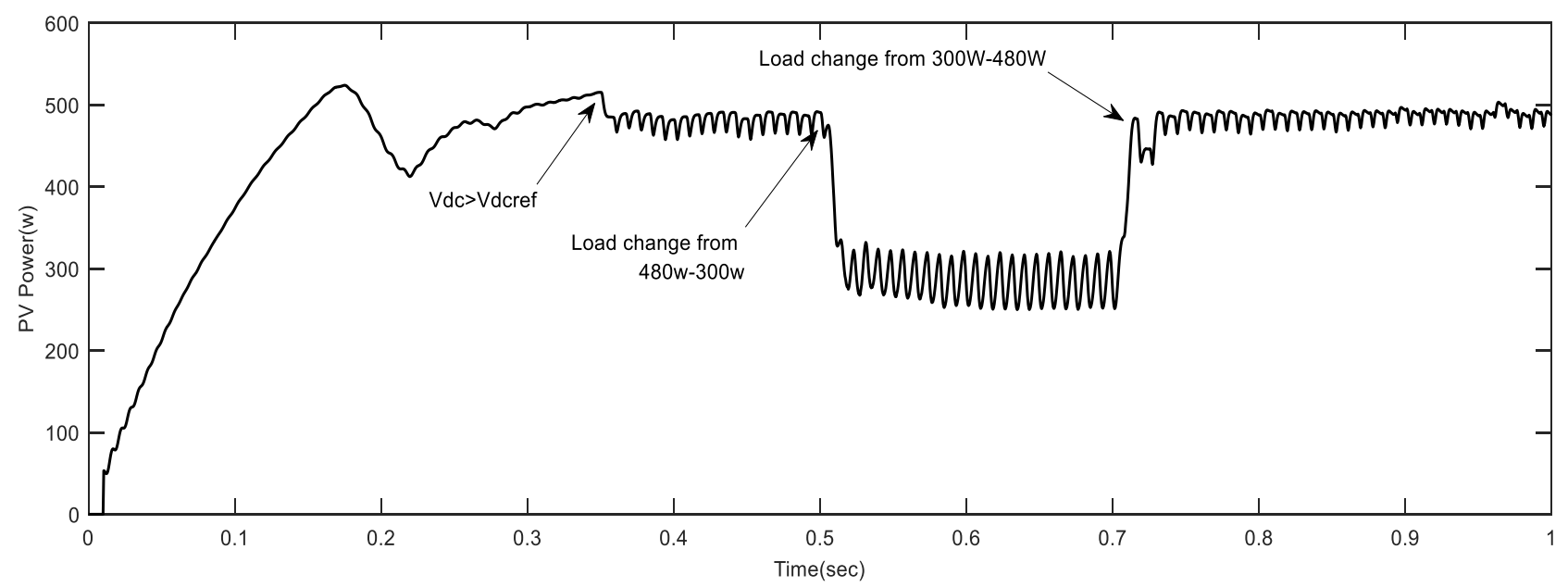

Figure. 16 PV power when load is suddenly changed from $480 \mathrm{~W}$ to $300 \mathrm{~W}$ in islanded operation

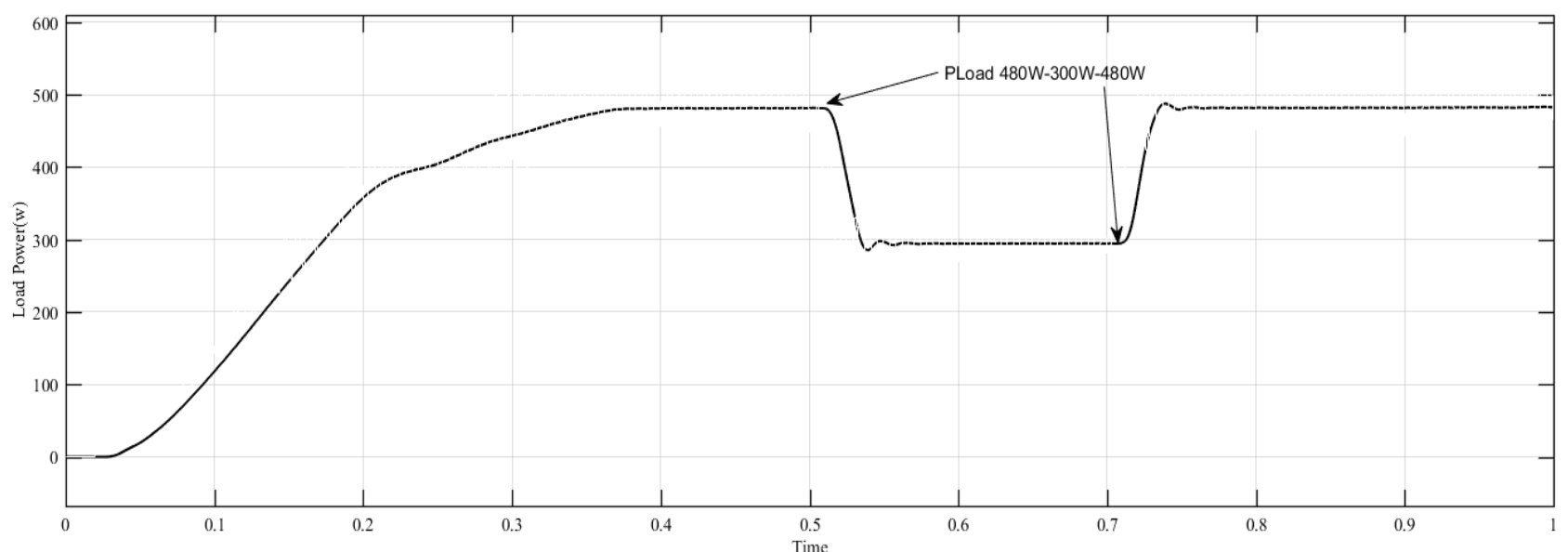

Figure. 16 Change in AC power delivered to load due to sudden load change from $0.4 \mathrm{sec}$ to $0.7 \mathrm{sec}$
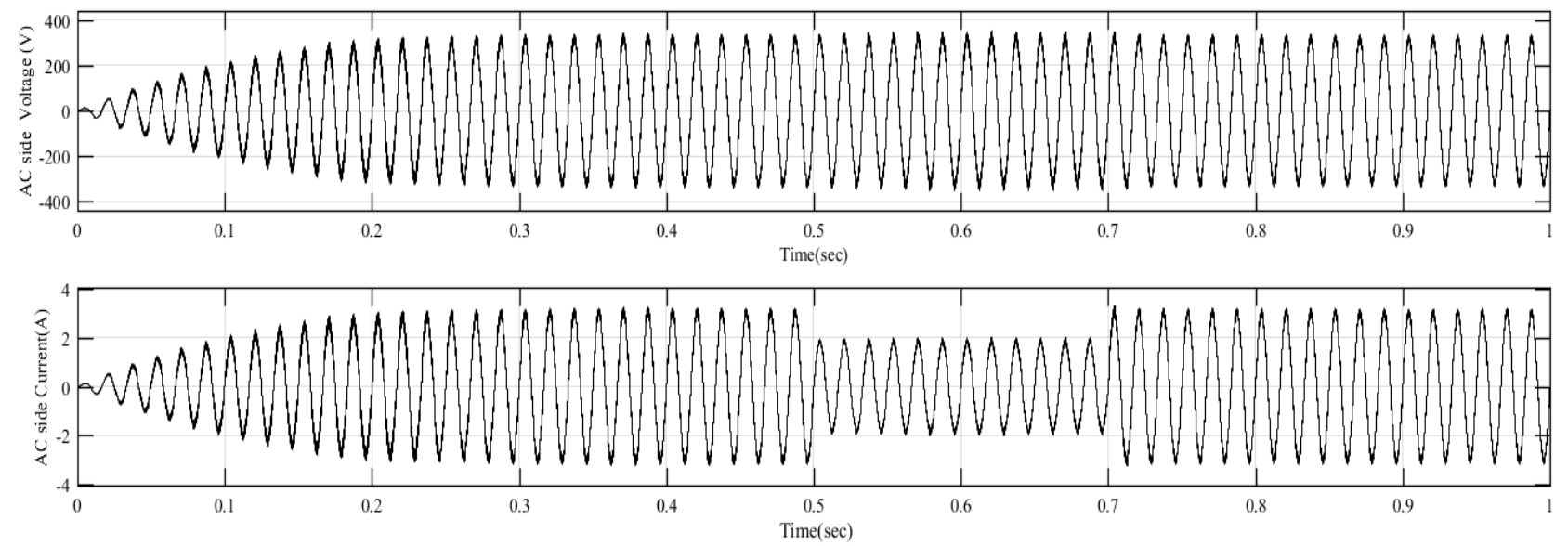

Figure. 17 Change in AC load Current due to sudden load change from $0.4 \mathrm{sec}$ to $0.7 \mathrm{sec}$

Fig. 18 (a) depicts the load sharing between DGs of different rating with different droop coefficients and Fig. 18 (b), for load sharing between DGs of same rating and with same coefficients $m l=m 2=150$ respectively. We can notice the difference of droop contributions of the distributed generators clearly with change in load between 0.6 and $0.8 \mathrm{sec}$. But in both the waveforms there is a sudden raise in current at $0.3 \mathrm{sec}$ as DC bus voltage crossed its reference value which activates -negative $d p / d v$ command signal to regulate DC bus voltage at $400 \mathrm{~V}$, thus increased voltage causes increased load sharing. 


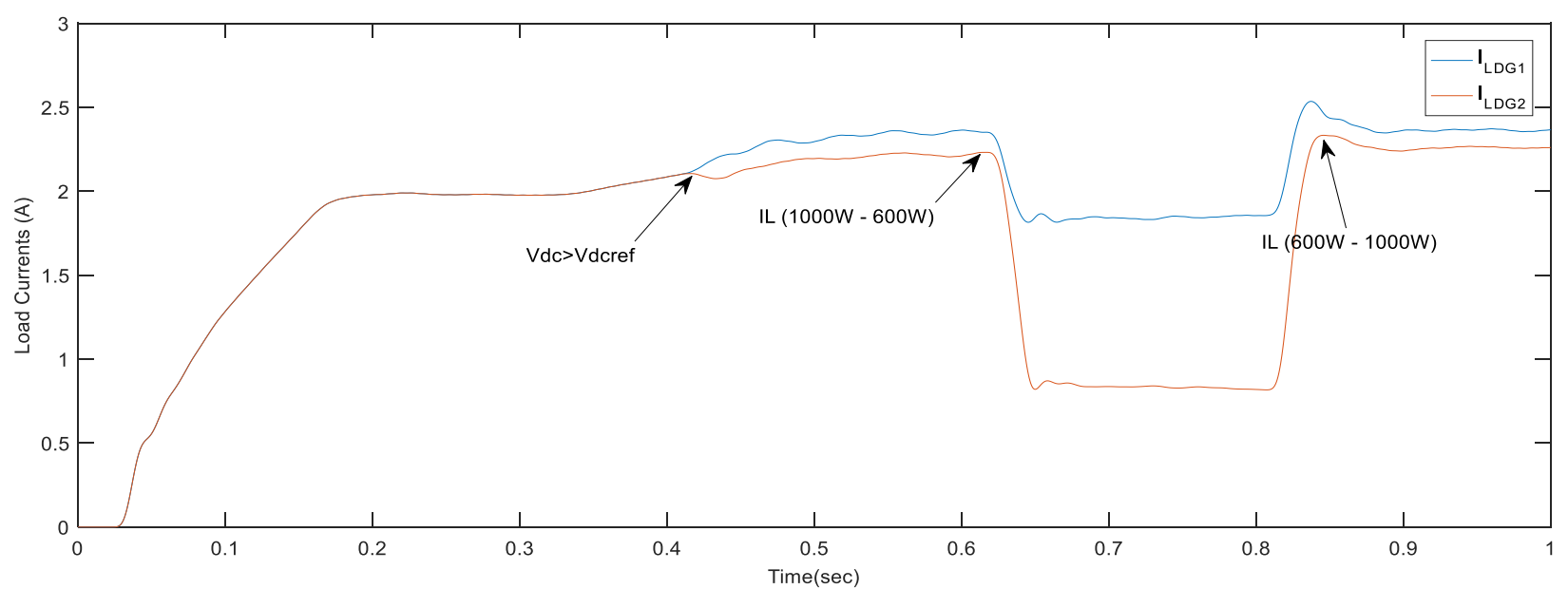

(a)

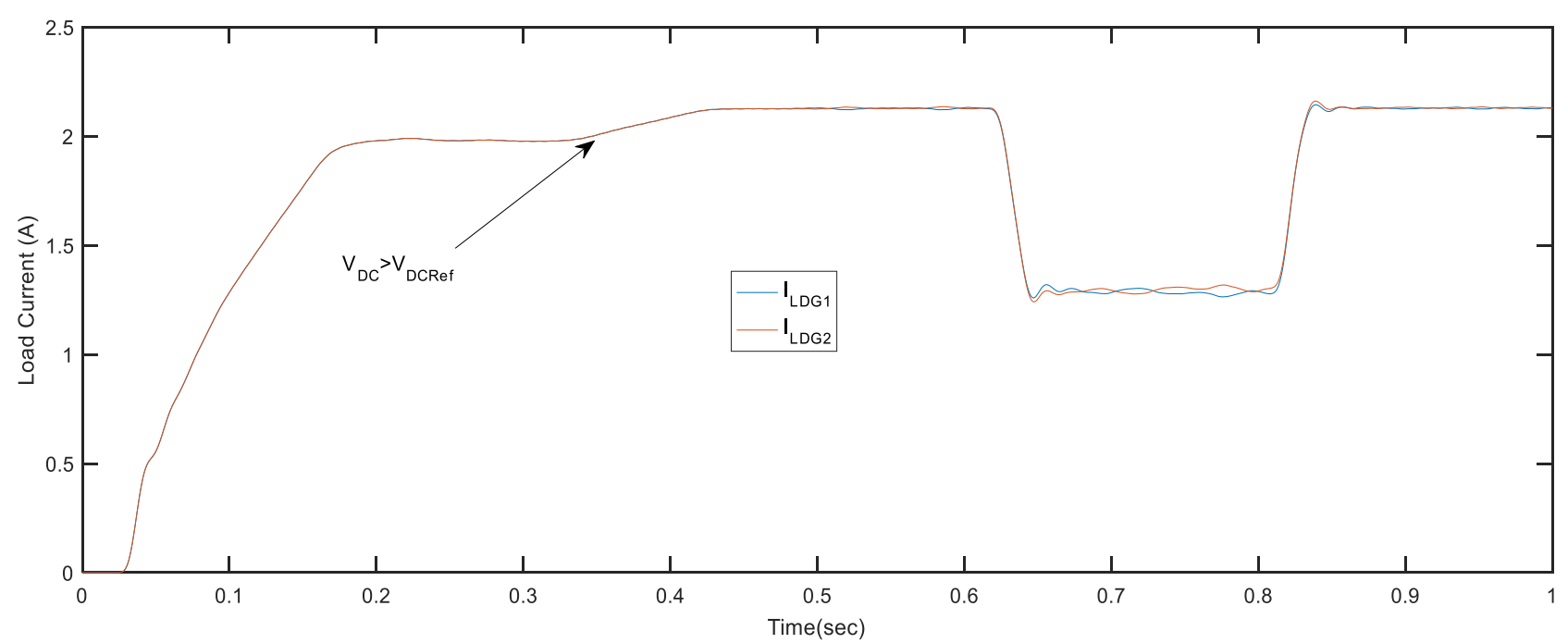

(b)

Figure. 18 Load sharing: (a) load current sharing between two DGs of similar rating (500W each) but with different droop coefficients and (b) load sharing between two DGs of similar rating and same droop coefficients
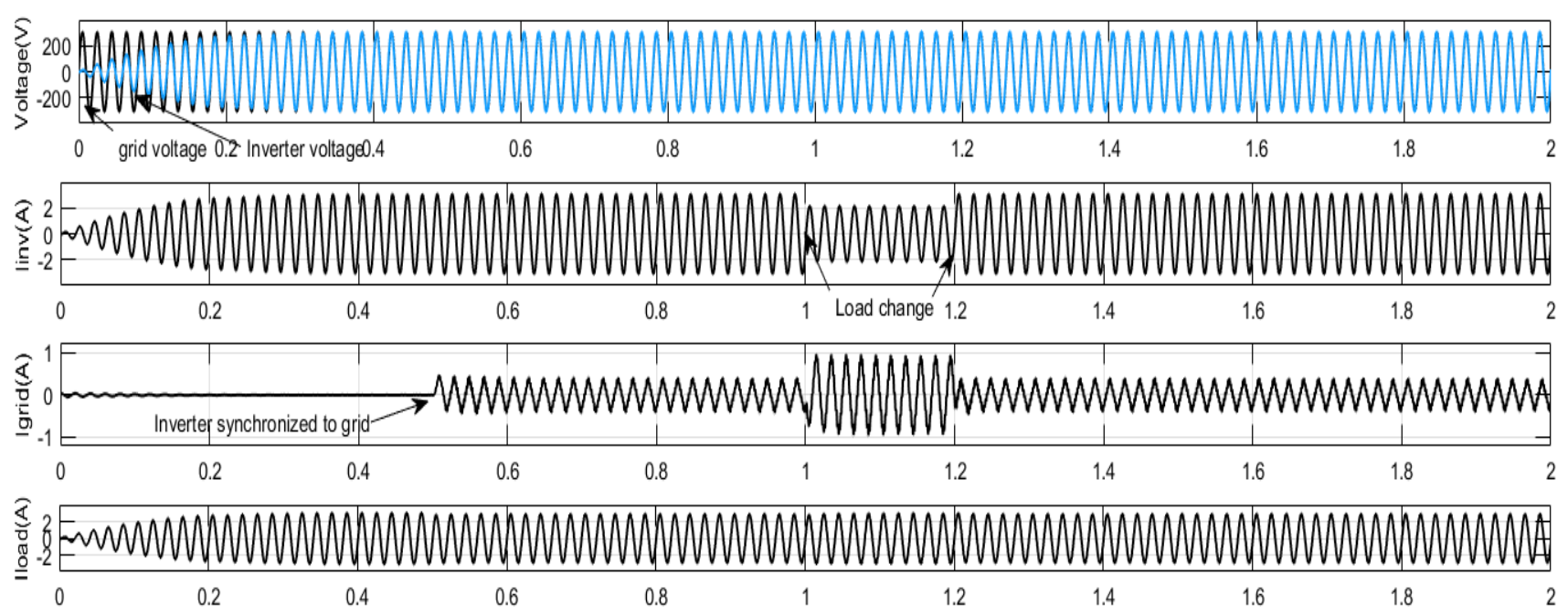

Figure. 19 Inverter and grid Voltage, Load (Iload), Grid (Igrid), Inverter (Iinv) current waveforms 
Table 4. Load sharing between Distributed generating sources.

\begin{tabular}{|l|l|l|}
\hline Parameter & $\begin{array}{l}\text { Modified } \\
\text { Method }\end{array}$ & $\begin{array}{l}\text { Existing } \\
\text { Method }\end{array}$ \\
\hline $\begin{array}{l}\text { Load Sharing } \\
\text { when for DG1 } \\
\text { is m1=50 and for } \\
\text { DG2 is } \\
\text { m2=150,when } \\
\text { load changes } \\
\text { from 1000W to } \\
\text { 600W }\end{array}$ & $\begin{array}{l}\text { ILDG1=1.716A } \\
\text { ILD2=2.616 }\end{array}$ & Not Considered \\
(60\% of4.34) & \\
$\begin{array}{l}\text { Load Sharing } \\
\text { when both DG1 } \\
\text { \& DG2 is } \\
\text { m1=m2=150,wh } \\
\text { en load changes } \\
\text { from 1000W to } \\
\text { 600W }\end{array}$ & $\begin{array}{l}\text { IL2=2.616 } \\
\text { (60\% of4.34) }\end{array}$ & \\
\hline
\end{tabular}

Thus the control structure shown in Fig. 5(b) responsible not only for Maximum power point tracking (MPPT), Battery State of charge (SOC) control of battery and DC voltage regulation.

iv) Fig. 19, shows Inverter/Grid voltage waveforms, from 0 to $0.5 \mathrm{sec}$ DG is operated in Islanded mode, at $0.5 \mathrm{sec}$, is synchronized to grid by means of synchronizing switch. Load is changed is between 1 to $1.2 \mathrm{sec}$ such that load maximum current value decreased from $3 A$ to $2 A$ peak and corresponding change in load current and grid currents are shown. When load current decreases, the DG feeds its excess current i.e., $i_{\text {grid }}=i_{d g}-$ $i_{\text {load }}-i_{\text {batt }}$ to grid.

\section{Conclusion}

Solar and Battery based Transformer coupled dual input DC-DC converter is considered and improvised its DC side control strategy in such a way that, MPPT, Battery SOC control, Voltage Regulation and Load sharing in one control strategy. Thus, avoided the necessity of mode switching and improvised the DC bus voltage profile at DC bus compared to existing method, when system is subjected to load changes in Islanded condition. This proposed control strategy not only does the voltage regulation, but also does load sharing based on droop control technique and also works with both Islanded and grid-connected modes of operation. Future scope of this work includes extending this droop control technique for AC-DC microgrid with necessary power control strategies.

\section{Acknowledgments}

We thank Dr.M Syam sundar, Assistant professor in English, PVP Siddhartha Institute of Technology, for comments that greatly improved the manuscript.

\section{References}

[1] S.Adhikari and F. Li, "Coordinated V-f and P-Q Control of Solar Photovoltaic Generators With MPPT and Battery Storage in Microgrids", IEEE Trans. Smart Grid, Vol. 5, No. 3, pp. 1270-1281, 2014.

[2] M. Miyatake, M. Veerachary, F. Toriumi, N. Fujii, and H. Ko, "Maximum power point tracking of multiple photovoltaic arrays: A PSO approach", IEEE Trans. Aerosp. Electron. Syst., Vol. 47, No. 1, pp. 367-380, 2011.

[3] J. Zeng, W. Qiao, and L. Qu, "An isolated multiport DC-DC converter for simultaneous power management of multiple renewable energy sources", In: Proc. of 2012 IEEE Energy Convers. Congr. Expo. ECCE 2012, pp. 37413748, 2012.

[4] T.-F. Wu, C.-H. Chang, Z.-R. Liu, and T.-H. Yu, "Single-stage converters for photovoltaic powered lighting systems with MPPT and charging features", In: Proc. of IEEE Appl. Power Electron. Conf. Expo. - APEC, Vol. 2, pp. 1149-1155, 1998.

[5] D.D. C. Lu and V. G. Agelidis, "Photovoltaicbattery-powered DC bus system for common portable electronic devices", IEEE Trans. Power Electron., Vol. 24, No. 3, pp. 849-855, 2009.

[6] D. Debnath and K. Chatterjee, "Two-Stage Solar Photovoltaic-Based Stand-Alone Scheme Having Battery as Energy Storage Element for Rural Deployment", IEEE Transactions on Industrial Electronics, Vol. 62, No. 7, pp. 41484157, 2015.

[7] D. Debnath and K. Chatterjee, "Transformer coupled multi-input two stage standalone solar photovoltaic scheme for rural areas", In: Proc. of IECON 2013 - 39th Annual Conference of the IEEE Industrial Electronics Society, pp. 70287033, 2013.

[8] S. H. Hosseini, F. Nejabatkhah, S. Danyali, and S. a Kh, "Grid-Connected Three-Input PV / FC / Battery Power System with Active Power Filter Capability”, In: Proc. of IEEE Conf., pp. 1-7, 2011.

[9] B. Papari, C. S. Edrington, I. Bhattacharya, and G. Radman, "Effective Energy Management of Hybrid AC-DC Microgrids with Storage 
Devices", IEEE Trans. Smart Grid, Vol. 3053, No. c, pp. 1-10, 2017.

[10] X. Lu, J. M. Guerrero, K. Sun, and J. C. Vasquez, "An improved droop control method for dc microgrids based on low bandwidth communication with dc bus voltage restoration and enhanced current sharing accuracy", IEEE Trans. Power Electron., Vol. 29, No. 4, pp. 1800-1812, 2014.

[11] Shivam and R. Dahiya," Intelligent Distributed Control Techniques for Effective Current Sharing and Voltage Regulation in DC Distributed Systems", Arabian Journal for Science and Engineering, Vol. 42, No. 2, pp. 5071-6081, 2017.

[12] J. Rajagopalan, K. Xing, Y. Guo, F. C. Lee, and B. Manners, "Modeling and dynamic analysis of paralleled DC/DC converters with master-slave current control", In: Proc. of Applied Power Electronics Conference. APEC '96, Vol. 2, pp. 678-684, 1996.

[13] V. Nasirian, S. Moayedi, A. Davoudi, and F. L. Lewis, "Distributed Cooperative Control of DC Microgrids", IEEE Transactions on Power Electronics, Vol. 30, No. 4, pp. 2288-2303, 2015.

[14] V. Nasirian, S. Moayedi, A. Davoudi, and F. L. Lewis, "Distributed Cooperative Control of DC Microgrids", IEEE Transactions on Power Electronics, Vol. 30, No. 4, pp. 2288-2303, 2015.

[15] R. K. Sharma and S. Mishra, "Dynamic Power Management and Control of a PV PEM FuelCell-Based Standalone ac/dc Microgrid Using Hybrid Energy Storage", IEEE Transactions on Industry Applications, Vol. 54, No. 1, pp. 526538, 2018.

[16] Y. Gu, W. Li, and X. He, "FrequencyCoordinating Virtual Impedance for Autonomous Power Management of DC Microgrid", IEEE Transactions on Power Electronics, Vol. 30, No. 4, pp. 2328-2337, 2015.

[17] M. Nasir, H. A. Khan, A. Hussain, L. Mateen, and N. A. Zaffar, "Solar PV-Based Scalable DC Microgrid for Rural Electrification in Developing Regions", IEEE Transactions on Sustainable Energy, Vol. 9, No. 1, pp. 390-399, 2018.

[18] W. Yuan, J. Yang, Y. Sun, H. Han, X. Hou, and M. Su, "A novel operation mode for PV-storage independent microgrids with MPPT based droop control", In: Proc. of 2017 IEEE 3rd International Future Energy Electronics Conference and ECCE Asia, pp. 936-941, 2017.

[19] B. John, A. Ghosh, and F. Zare, "Load Sharing in Medium Voltage Islanded Microgrids with
Advanced Angle Droop Control", IEEE Transactions on Smart Grid, Vol. 9, No. 6, pp. 6461-6469, 2017.

[20] Y. Han, H. Li, P. Shen, E. A. A. Coelho, and J. M. Guerrero, "Review of Active and Reactive Power Sharing Strategies in Hierarchical Controlled Microgrids", IEEE Transactions on Power Electronics, Vol. 32, No. 3, pp. 24272451, 2017.

[21] B. Mangu and B. G. Fernandes, "Multi-input transformer coupled DC-DC converter for PVwind based stand-alone single-phase power generating system", In: Proc. of 2014 IEEE Energy Conversion Congress and Exposition, pp. 5288-5295, 2014.

[22] B. Mangu, S. Akshatha, D. Suryanarayana, and B. G. Fernandes, "Grid-Connected PV-WindBattery-Based Multi-Input TransformerCoupled Bidirectional DC-DC Converter for Household Applications", IEEE Journal of Emerging and Selected Topics in Power Electronics, Vol. 4, No. 3, pp. 1086-1095, 2016.

[23] H. Cai, J. Xiang, W. Wei, and M. Z. Q. Chen, "V-dp/dv Droop Control for PV Sources in DC Microgrids", IEEE Transactions on Power Electronics, Vol. 33, No. 9, pp. 7708-7720, 2018.

[24] M. G. Molina and P. E. Mercado, "Modeling and control of grid-connected photovoltaic energy conversion system used as a dispersed generator", In: Proc. of 2008 IEEE/PES Transmission and Distribution Conference and Exposition: Latin America, pp. 1-8, 2008.

[25] J. A. Gow and C. D. Manning, "Development of a photovoltaic array model for use in powerelectronics simulation studies", In: IEEE Proceedings - Electric Power Applications, Vol. 146, No. 2, pp. 193-200, 1999. 